\title{
THE NOMINAL STRUCTURE OF CLAUSAL COMPLEMENTS: AN EXPERIMENTAL STUDY OF WH-EXTRACTION IN BULGARIAN
}

\author{
Arthur Stepanova, Iliyana Krapovab \\ University of Nova Gorica ${ }^{a}$, Ca'Foscari University of Venice ${ }^{b}$
}

arthur.stepanov@ung.si ${ }^{\mathrm{a}}$,krapova@unive.it ${ }^{\mathrm{b}}$

\begin{abstract}
We explored the nominal structure of finite clausal complements of propositional attitude verbs in Bulgarian by examining potential complex NP island effects in wh-extraction out of these complements. A complex NP island structure is signaled by the presence of an overt correlative pronoun tova preceding the finite complement. We compared speakers' judgments and reading patterns concerning wh-extraction out of complements preceded by overt correlative pronoun tova and those in which no overt correlative is present, in an acceptability judgment experiment using a factorial design. The experiment also included an online reading time task. We found that factors structure and dependency length affect acceptability of wh-dependencies with and without an overt correlative independently, but there was no additive effect. We conclude that both subtypes of clausal complements, with and without an overt correlative, are essentially island-like configurations, which supports the nominal structure hypothesis for Bulgarian. The reading time data also allowed us to track down interesting patterns of compatibility of different verbs with an overt correlative.
\end{abstract}

Keywords: wh-extraction, experimental syntax, propositional attitude verb, Bulgarian

\section{Introduction}

The categorial status of finite complements of propositional attitude verbs such as believe or claim has long been under debate in the generative syntactic literature. ${ }^{16}$ According to the traditional view dating back to Emonds (1970) and Stowell (1981) and commonly adopted in the current syntactic theorizing, finite complements of these verbs are categorially clauses, or Complementizer Phrases (CP) selected by the verb and headed by complementizers such as that (in English). The alternative view, that a complement CP is engulfed within an NP "shell" headed by an overt or silent noun or determiner, often referred to as a correlative proform, goes back to Rosenbaum (1967). It has been entertained at various points within the late Government and Binding (GB) and early Minimalist literature and is recently witnessing a resurging interest among syntacticians (see below for references). Both views are schematized in (1):

$$
\begin{aligned}
& \text { (1) a. } \mathrm{V}_{\text {prop }}\left[{ }_{\mathrm{CP}} \mathrm{C} \ldots\right] \\
& \text { b. } \mathrm{V}_{\text {prop }}\left[{ }_{\mathrm{NP}} \mathrm{N}\left[{ }_{\mathrm{CP}} \ldots\right]\right]
\end{aligned}
$$

The continuing attention to the issue is driven, not in the least, by ensuing consequences concerning transparency / opacity of syntactic dependencies across the finite clausal boundary. Indeed, on most known accounts, the NP approach to complementation a priori predicts a complex NP island-like effect regarding extraction out of a finite complement. A construction at issue is long-distance wh-questions as in (2):

(2) Who does Peter believe $\left[_{\mathrm{CP}}\right.$ (that) Boris saw at the market $]$ ?

\footnotetext{
${ }^{16}$ In broad terms, propositional attitude verbs are verbs that signal some degree of certainty regarding a concept formed in the mind, the expression of a speaker's attitude, judgment or opinion regarding a state of affairs in the complement clause. The class of propositional attitude predicates standardly include verbs like think, believe, know, want, which express an attitude towards the embedded proposition. In more recent literature (cf. White et al. 2018), so-called 'assertives' like claim, say, acknowledge have been added to this class for two reasons: a) such verbs express report of a propositional attitude and b) their complement clause supplies a 'mental picture' or a 'judgement of truth' on the part of the main clause subject or the speaker, much like with standard propositional attitude verbs.
} 
As (2) shows, no such effect is apparent in English, which a priori supports view (1a). Yet structural counterparts of questions as in (2) have been reported to have a degraded status, in particular, in Polish, Russian (e.g., Stepanov 2006) and some varieties of German (Fanselow, Weskott 2010), to name just a few examples. This degradation has been attributed to a complex NP-like island effect due to wh-extraction across an NP shell headed by a silent correlative which demarcates the complement clause in these languages, in favor of view (1b) (see also Müller, Sternefeld 1995). In light of grammaticality of (2), the choice among two basic views on complementation in (1) entails a corresponding analytic strategy as regards the empirical contrast at issue. There are three possibilities: i) both structures (1a) and (1b) are attested Universal Grammar (UG) options, perhaps representing two values of a structural parameter responsible for cross-linguistic variation; ii) only structure (1a) is available in UG, and the additional layer of structure in (1b) is in some sense idiosyncratic or language-specific; and iii) only the nominal structure (1b) is available in UG, and clausal structure (1a) is derived from it by some form of structural reduction. Stepanov (2001) and Stepanov and Stateva (2006) argue for option iii) which avoids postulating languagespecific structures or phrase structural parameters, while at the same time predicting a complex NP effect in the counterparts of (2) in the languages mentioned above. ${ }^{17}$ Their argument is built around the observation that the correlative $\mathrm{N}$ head typical for the structure in $(1 \mathrm{~b})$ may actually surface overtly in these languages. Indeed, long-distance wh-extraction out of a complement preceded by an overt correlative induce a clear complex NP effect in these languages. At the same time, wh-extraction out of complements without the overt correlative often results in a dubious acceptability status: while speakers agree that they are not perfect, the degree of degradation has so far been somewhat difficult to pinpoint. This kind of empirical obstacle prevents a firm conclusion concerning the uniformity of the NP-shell structure, especially in cases when no overt correlative is present.

This paper reports a work in progress exploring the nominal structure of clausal complementation in Bulgarian by looking into patterns of acceptability of wh-extraction out of complements of propositional attitude verbs in this language. An a priori consensus seems to be that these are generally acceptable, similarly to English, but informal inquiries indicate that a good deal of variability exists across speakers and verb types. Our starting point is that, similarly to Russian and Polish, clausal complements of propositional attitude verbs in Bulgarian may be optionally preceded by an overt correlative, tova 'it'. ${ }^{18}$
(3) Rektorat
saobshti (tova),
che studentat e sreshtnal
dekana pred
hotela
the-rector reported it
that the-student is met
the-dean in-front-of
the-hotel
'The rector reported that the student met the dean in front of the hotel'

That the correlative structurally "belongs" in the embedded clause can also be seen in sentences where the clause is not in the complement position:

(4) [Tova, che studentat e sreshtnal It that the-student is met

dekana pred hotela] e trudno za vyarvane 'That the student met the dean in front of the hotel is hard to believe'

If tova indicates an NP-shell structure, similarly to other languages mentioned above, then the acceptability status of long wh-questions without the overt correlative would provide a critical evidence concerning the uniformity of NP-shell structure in this language. All else being equal, a degraded status of a long wh-question in the absence of overt correlative would indicate the presence of an NP-shell structure (with an $\mathrm{N}$ being possibly null or silent) and that the degradation is due to a complex NP effect. If no degradation is found, then one of two explanations is conceivable: either a) no NP-shell structure is activated, or b) a structural reduction similar to that postulated for English (see above) takes place in Bulgarian as well. The present study aims to shed light within the space of these possibilities.

\footnotetext{
17 These authors argue that in English, a silent correlative pronoun starts out heading an NP-shell as well, but later undergoes a fusion with a selecting verb effectively collapsing the NP-shell structure and voiding the islandhood for the purposes of wh-extraction out of an embedded clause. See also Müller, Sternefeld (1995).

18 The actual use of the version with the overt correlative is often restricted to a subset of contexts that we will not discuss here. We also assume that the correlative itself is semantically vacuous, following the proposal in Stepanov, Stateva (2006) for a similar construction in Russian.
} 
As noted above, speakers' judgments concerning long wh-questions are often uncertain, given the overall complexity of the construction that intervenes in the introspective process. As such, they cannot be placed within a binary continuum (viz. acceptable or unacceptable). Rather, in most cases, these judgments can be quantified as some gradient of perfect acceptability varying across speakers. This state of affairs calls for a larger-scale acceptability judgment study in order to reliably register this inter-speaker variation. Recent research in experimental syntax focusing on a range of different island effects suggests that two external factors may play a key role in affecting acceptability judgments in island-inducing constructions: the length of a wh-dependency (in case of a long wh-question, extending across the complement clause boundary) and availability of complex structure (Sprouse et al. 2016, Stepanov et al. 2018, Kush et al. 2019, among others).

We reasoned that by isolating these external factors the true acceptability status of Bulgarian longdistance wh-questions without an overt correlative can be deduced with greater clarity. Specifically, we wanted to compare speakers' performance using an experimental design crossing length of a wh-dependency (short, long) and structure (presence / absence of overt correlative). The resulting four experimental conditions are exemplified below:

(5) a. Koy saobshti, che studentat e posreshtnal rektora pred hotela? who reported that the-student is met the-rector in-front-of the-hotel 'Who reported that the student met the rector in front of the hotel?' [short, -corr]

b. Koy saobshti tova, che studentat e posreshtnal rektora pred hotela? who reported it that the-student is met the-rector in-front-of the-hotel 'Who reported that the student met the rector in front of the hotel?' [short, +corr]

c. Kogo rektorat saobshti, che studentat e posreshtnal pred hotela? whom the-rector reported that the-student is met in-front-of the-hotel 'Who did the rector report that the student met in front of the hotel?' [long, -corr]

d. Kogo rektorat saobshti tova, che studentat e posreshtnal pred hotela? Whom the-rector reported it that the-student is met in-front-of the-hotel 'Who did the rector report that the student met in front of the hotel?' [long, +corr]

In line with previous experimental studies on island effects, we expected that each of the two factors is likely to lower the acceptability independently (see the references above). That is, a wh-question with an overt correlative is likely to receive lower acceptability than without one. Similarly, a question involving a long wh-dependency should receive a lower acceptability than one involving a short wh-dependency. This hypothetical situation is depicted on the left graph in Figure 1. A true island effect in this design manifests itself as an additive effect of the two factors at issue. Specifically, if there is a true complex NP island effect due to the overt correlative, the factorial design will detect it in at least two different ways. Statistically, it will show up as a significant interaction between factors length and structure. Graphically, the lines connecting points corresponding to the short and long wh-dependencies will not be parallel. This situation is depicted on the right graph in Figure 1.
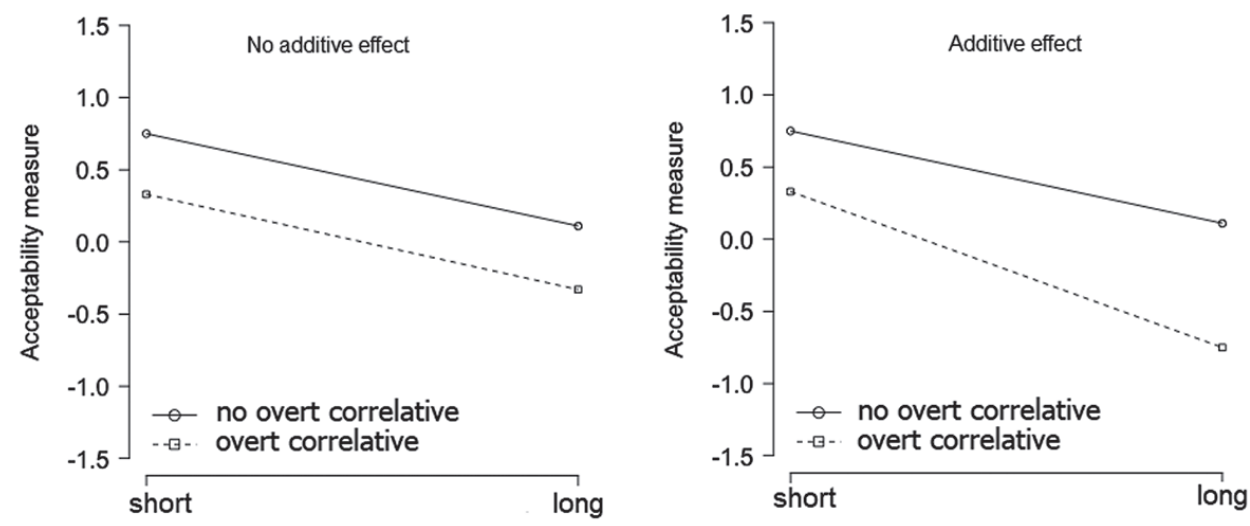

Figure 1. Two hypothetical outcomes of a $2 \times 2$ design crossing length of wh-dependency and availability of overt correlative 
In addition to detecting a complex NP island effect with an overt correlative, we hoped to be able to make additional conclusions regarding the structure of long-distance dependency without one. Indeed, if the design reveals an additive / true island effect with the overt correlative, and its absence without one, this result would not support the nominal structure of clausal complementation in Bulgarian. In contrast, the absence of an additive effect with the overt correlative would be consistent with two interpretations: i) either there is no island effect with the overt correlative (an unlikely outcome, by all available evidence and intuitions), or ii) the island effect persists also without the overt correlative, consistent with the nominal structure of clausal complementation in Bulgarian as in (1b). We reflect on the second possibility in more detail in Section 4.

\section{Method}

To test the above predictions, we conducted an acceptability judgment task in a controlled experiment using a factorial design, specifically, crossing the wh-dependency length ([short], [long]) and structure ([+corr], [-corr]) in a 2 x 2 fashion as outlined above (cf. (5)). In addition, we included a selfpaced reading component in our experiment. The majority of experimental syntax studies investigating island effects in the literature so far were based on the offline acceptability judgment paradigm. At the same time, findings in behavioral psycholinguistics indicate that island structures including complex NP islands, in addition to eliciting speakers' global judgment of mild to strong unacceptability, also trigger online effects at critical point(s) when an island structure is encountered in a reading task. These online effects include, in particular, increased reading times associated with processing complexity (e.g., see Hofmeister, Sag 2010 for complex NP islands). The primary purpose of including a reading time component in our manipulation was therefore to see if our tested Bulgarian speakers are sensitive to the potential complex NP island status of the clausal complement signaled by an overt correlative, in addition to the global acceptability evaluation of sentences with and without overt correlative. We deemed this combination of online and offline measures as potentially revealing a more fine-grained picture that bears on the nominal structure of clausal complements in cases when no overt correlative is available.

\subsection{Experimental materials}

Materials included 12 blocks of complex wh-questions beginning with koy "who" or kogo "whom". A sample block is illustrated in (5) above. Because our primary focus of interest was on clausal complements of propositional attitude verbs, we carefully chose a subset of those verbs that allow overt correlative tova preceding their clausal complement. In particular, the following verbs were used in the matrix clause: ${ }^{19}$

(6) kazvam 'say', priznavam 'admit', zabravyam 'forget', pomnya 'remember', znam 'know', predpolagam 'suppose', saobshtavam 'report', dopuskam 'assume', obyasnyavam 'explain', tvardya 'claim', prenebregvam 'ignore', podoziram 'suspect'

The chosen set of predicates can be further classified along various secondary dimensions, such as assertivity, factivity and communicativity, but the exact semantic typologization is not important for the present purposes (e.g., see White et al. 2018 for a recent discussion of cognitive aspects of propositional attitude verbs and Krapova 2020 for discussion of factive verbs in Bulgarian). ${ }^{20}$ Composition of the stimuli is exemplified in (5). The complement clause consisted of an animate definite subject NP, 3p.sg. past tense auxiliary $e$, a transitive verb in the past form followed by an animate definite object NP, and a wrap-up in

19 The selection in (6) excludes all preferential propositional attitude verbs because, in Bulgarian, they systematically select for a subjunctive clause irrespectively of whether their semantics is factive (want, wish, desire, prefer) or not (love, hate). Thus, only verbs that select for an indicative complement introduced by the declarative complementizer che 'that' have been considered for the purposes of this experiment.

${ }^{20}$ Long-distance wh-questions built around semantic counterparts of the predicates in (2) in English and other languages are grammatical if the most embedded wh-object is extracted, and are in some cases less grammatical if a wh-subject or wh-adjunct are extracted (cf. "weak islands"). 
the form of a locative or temporal adjunct. In the [long] conditions, the embedded object NP was converted to a wh-phrase kogo 'whom' undergoing long wh-extraction.

Target items within the blocks were counterbalanced in a Latin square fashion, so that each participant saw 3 tokens of each of the four experimental conditions (cf. (5)). In addition, 30 grammatical filler sentences were included that approximated the target items by length, plausibility and general world knowledge, but did not include any of the complement selecting verbs in (6) to avoid a possible bias. In total, the experiment included 42 sentences.

\subsection{Participants}

37 self-reported native speakers of Bulgarian participated in this study ( 30 female, mean age $=43.4$, $\mathrm{SD}=18.7$, median age $=45$ ). They were all right-handed, had either normal or corrected vision and were naïve to the purposes of the study.

\subsection{Procedure}

Sentences were presented to the participants on a computer screen in a self-paced, "moving window" mode using the Ibex Farm platform for online psycholinguistic experiments (by Alex Drummond, http:// spellout.net). In this mode of presentation, a subject initially sees a series of dashes in place of the words in a sentence. By pressing the space bar, the first word in the sentence appears in place of the first dash. With each subsequent press of the space bar, the next dash is replaced with the corresponding word and the previous one is turned back to a dash, until the end of the sentence is reached. Participants were instructed to read the sentences at a natural pace and to be sure they understand what they read. Participants' attention was assessed via their acceptability scores on the filler sentences that were expected to be high under the present design. Based on this criterion, none of the data were excluded from the analysis. The order of items was pseudo-randomized for each participant. Following each sentence, participants were asked to provide an acceptability judgment on a 1 to 5 Likert scale with 1 marked as napalno nepriemlivo 'completely unacceptable' and 5 as napalno priemlivo 'completely acceptable'. The overall task took approximately 25-30 minutes to complete.

\section{Results}

For statistical analysis, we used linear mixed-effects models (Baayen et al. 2008) entering dependency length, structure and verb type as fixed factors. Participant and sentence item were entered as random factors. We report main effects and interactions using $\chi^{2}$ statistic and $p$ values based on the likelihood-ratio test used in an ANOVA-like procedure which compares models including a fixed factor in question with models without that factor. Analyses were performed using the "Ime4" package in R 4.0.2 (R Core Team 2020).

\subsection{Acceptability scores}

As expected, sentences in the [short, - corr] condition received the highest scores $(\mathrm{M}=4.18, \mathrm{CI} 95=[3.78$; $4.58])$, followed by the [short, + corr] condition $\left(\mathrm{M}=3.86, \mathrm{CI}_{95}=[3.46 ; 4.26]\right)$, then the [long, -corr] condition $\left(\mathrm{M}=2.43, \mathrm{CI}_{95}=[2.03 ; 2.83]\right)$, and finally the $[$ long, + corr $]$ condition $\left(\mathrm{M}=1.89, \mathrm{CI}_{95}=[1.49 ; 2.28]\right)$. There was a main effect of dependency length, with longer wh-dependencies receiving lower scores than short ones $\left(\chi^{2}=94.584, p<0.001\right)$, and of correlative structure, questions with overt correlative tova being less acceptable than those without $\left(\chi^{2}=14.426, p<0.001\right)$. Importantly for our purposes, there was no interaction between the two factors $\left(\chi^{2}=1.151, p=0.283\right)$. These results are illustrated in Figure 2.

Verb type was not a significant main predictor of acceptability scores $\left(\chi^{2}=6.396, p=0.846\right)$, although it interacted with structure $\left(\chi^{2}=21.117, p=0.03\right)$. Pairwise comparisons on the interaction term (not reported here for reasons of space) indicated that with some verbs speakers prefer the correlative over the no correlative option, while with other verbs the opposite is the case. Furthermore, speakers' preferences were negatively correlated (Pearson's $r=-0.628, t=-2.5541, d f=10, p=0.0287$ ). These results are illustrated in Figure 3. 


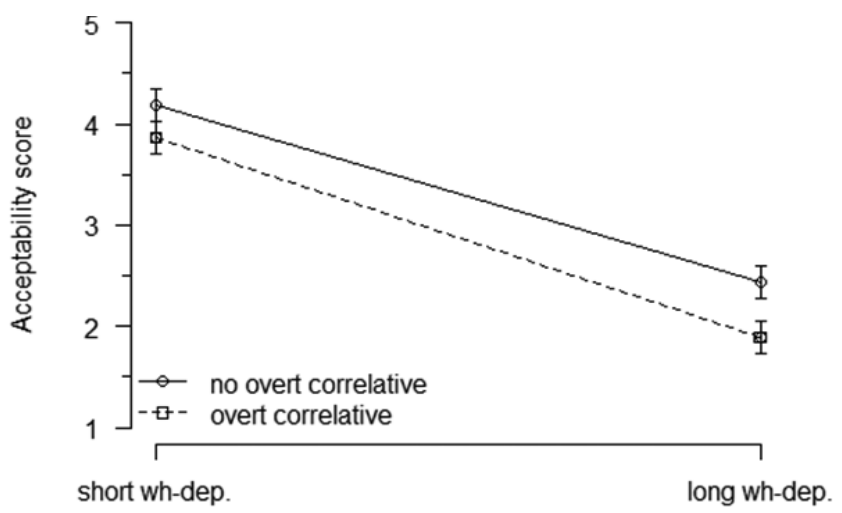

Figure 2. Distribution of acceptability judgments across the four conditions.

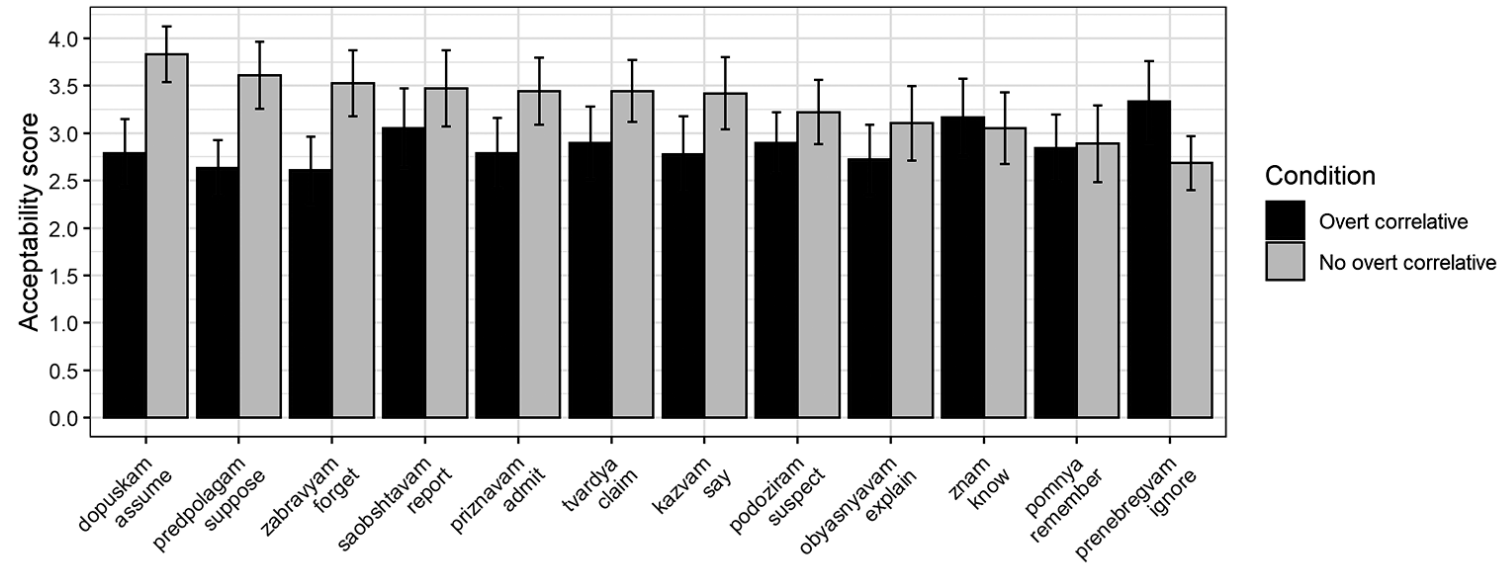

Figure 3. Comparison of acceptability scores per verb type (error bars show standard error).

\subsection{Reading times}

Reading times were measured per word. Reading times below $100 \mathrm{~ms}$ and above $4000 \mathrm{~ms}$ were trimmed as unlikely to be reflecting relevant linguistic processes. This affected $3.7 \%$ of the reading time data. We computed average reading times for each word position in all four conditions. These are shown in Figures 4 and 5.

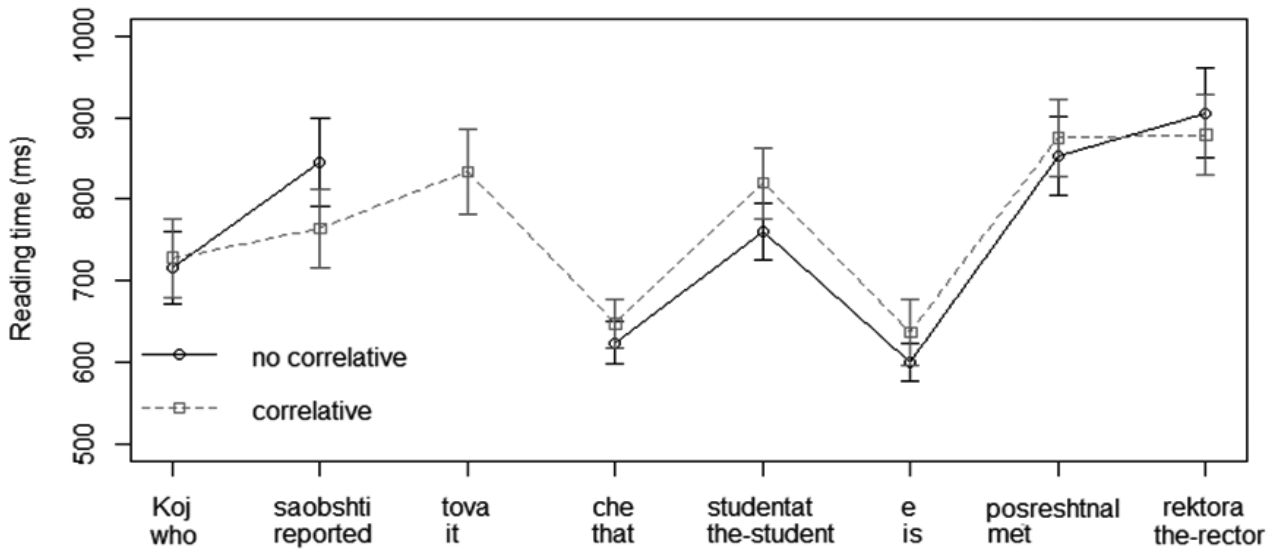

Figure 4. Time course of reading the sentences in the [short] conditions with and without the overt correlative (the last two word positions are not shown; error bars show standard error). 


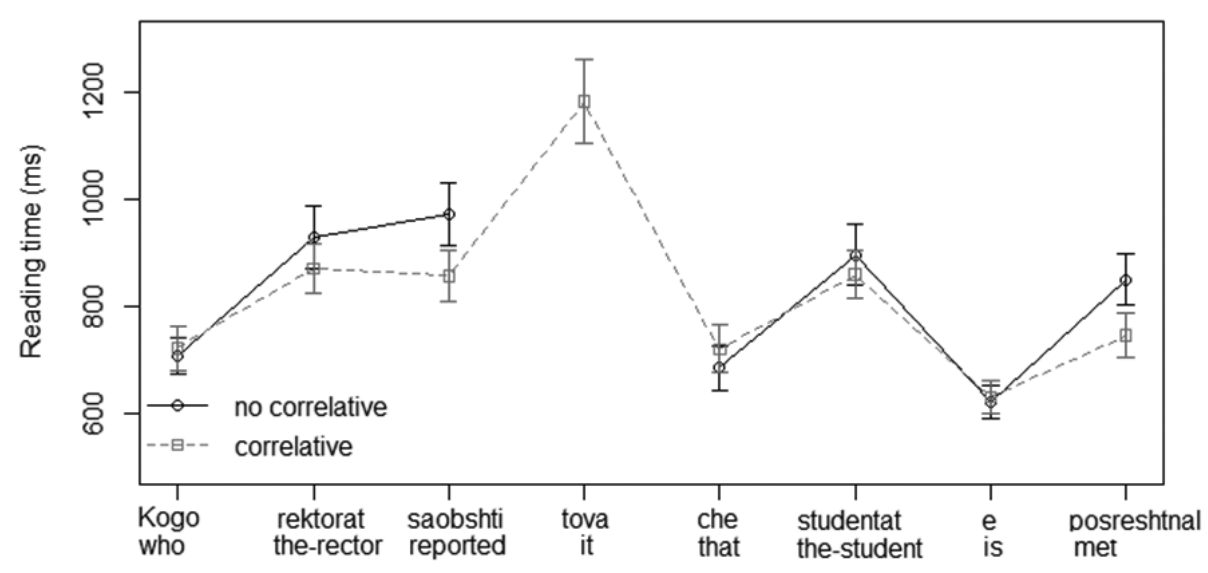

Figure 5. Time course of reading the sentences in the [long] conditions with and without the overt correlative (the last two word positions are not shown; error bars show standard error).

Except for the overt correlative, the time course of reading the target sentences was fairly consistent across conditions. Indeed, the correlative presents a greater surprise to the readers in the [long] condition while being read about $370 \mathrm{~ms}$ longer than in the [short] condition $(\beta=369.76, \mathrm{SE}=85.91, t=4.304$, $p<0.001)$. At the same time, the matrix verb region and the post-correlative regions did not differ in reading times regardless of the presence of the overt correlative, suggesting that the latter did not affect the overall reading pattern.

We were also interested in the time course of reading the overt correlative in combination with different verbs. To that end, we compared times of reading the overt correlative in both $[+$ corr] conditions (the $3^{\text {rd }}$ word in the [short, +corr] condition and the 4th word in the [long, +corr] condition) across the verb types. We observed a gradient of reading times across a continuum ranging from about 500 to $1800 \mathrm{~ms}$. This is shown in Figure 6.

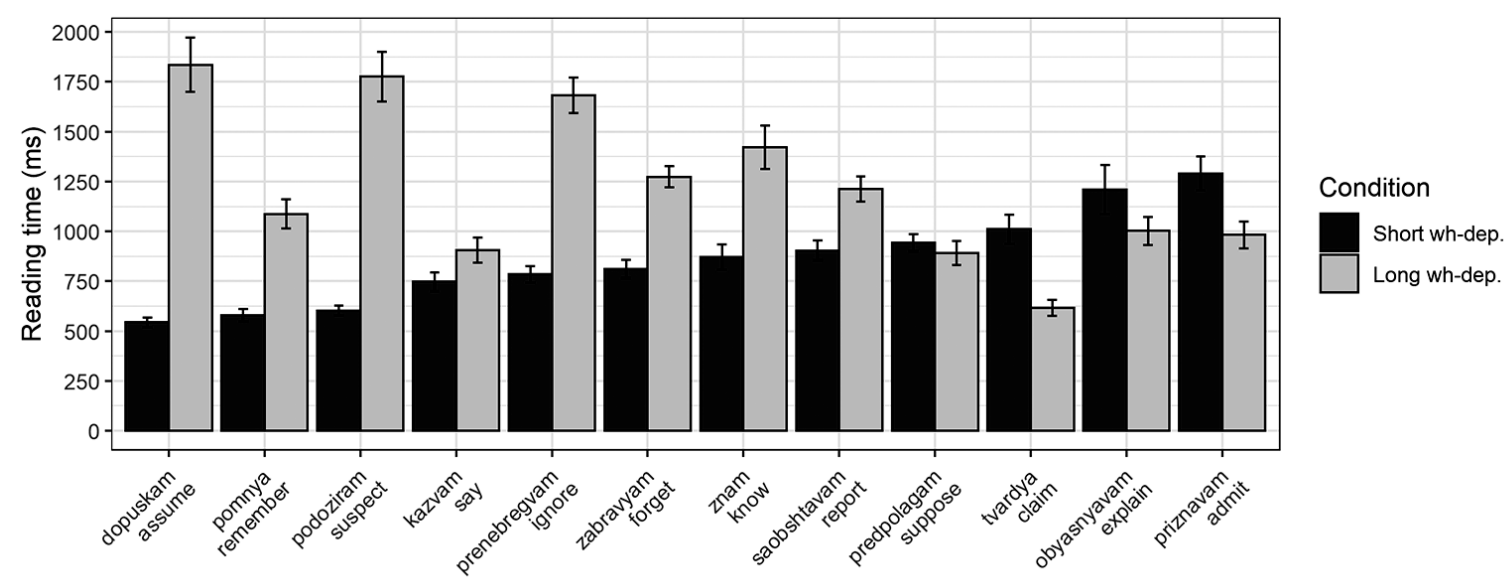

Figure 6. Comparison of reading times for the overt correlative per verb type (error bars show standard error).

Furthermore, we detected a negative correlation between the times of reading the correlative in the [short] and [long] conditions across the verb range (Pearson's $r(10)=-0.60, p=0.039$ ). In other words, the longer the time of reading the correlative in the [short] condition, the shorter it is in the [long] condition, and conversely. One can also discern this correlation from the trend in Figure 6 in which reading times are placed in an increasing order in reference to the [short] condition. 


\section{Discussion}

We begin the discussion with interpretation of the results of our acceptability judgment and online reading time tasks, followed by general consequences for the theory of clausal complementation in light of our predictions articulated in Section 1.

\subsection{Acceptability scores and the nominal structure}

Our two [+corr] conditions encoded sentences involving finite clausal complements preceded by an overt correlative. The wh-extraction structures in the $[$ long, +corr $]$ condition can reasonably be seen on a par with Complex NP configurations, thus a priori we expected their acceptability to be low. Indeed, this is what was found. Previous research has also shown that a true island effect can be isolated in a factorial experimental design as an additive effect of structure and dependency length factors (see the references in Section 1) in the form of a significant interaction. In our study, we observed no significant interaction of these two factors. This implies that the length factor affects acceptability of wh-extraction structures with the overt correlative just as much as it does those without the overt correlative, but not more. As pointed out in Section 1, such result is a priori compatible with two interpretations: either i) there is no true island effect with an overt correlative, or ii) an island effect persists also in wh-extraction sentences without the overt correlative (the [long, -corr] condition).

Option i) seems unlikely to us given the syntactic structure of the Bulgarian clausal complements with an overt correlative which indubitably signals a complex NP configuration (cf. (3) and (4)). The low acceptability of wh-extraction out of such complements in the [long, +corr] condition is therefore hard to explain otherwise if not in terms of an island effect. If, on the other hand, we take the island effect in the [long, +corr] condition for granted, then we are left with option ii), which at face values sounds like a paradox. Indeed, as mentioned above, the classic interpretation of the absence of an additive effect was that no true island effect is present (cf. the parallel lines on the left graph in Figure 1). In contrast, option ii) suggests that not only the island effect is present, but it extends also to wh-extraction without overt correlative. But this paradox can be resolved naturally if, informally speaking, instead of viewing the obtained acceptability scores on the [long, +corr] condition as "insufficiently low" compared to the [long, -corr] condition, we rather view the obtained acceptability of [long, -corr] sentences as "too low" compared to the $[$ long, +corr] sentences. In other words, a potential additive effect, expected on the null hypothesis, does not arise due to the low acceptability of sentences in the [long, -corr] condition, which indicates a latent complexity effect in that condition as well as in the [long, +corr] condition. The factorial design, as originally set up, is therefore not able to detect the islandhood of the [long, +corr] condition.

In syntactic terms, the fact that the participating subjects attended to both [long] conditions similarly suggests that the complexity effect is independent of the presence of overt correlative in the structure. Put differently, long wh-extraction out of clausal complements, at least with the tested set of selecting predicates, appears to induce a complex NP island-like effect in Bulgarian across the board. Assuming that the overt correlative occupies a syntactic position along the lines of the schema in (1b), and that the schema in (1b) is responsible for a Complex NP island effect, our results can be interpreted as population level evidence for generality of this schema in Bulgarian clausal complements regardless of the presence of overt correlative. This state of affairs supports the conjecture that complements without an overt correlative are headed by a null N or D head, in line with the previous proposals (cf. Section 1).

Our results are also instructive from the methodological perspective. Syntactic accounts postulating empty categories not directly detectable by surface (morphological or lexical) cues are often subject to critique only because potential evidence for these empty components may be hard to induce at the individual level. Here we see that a factorial experimental design yielded novel suggestive evidence for a latent nominal structure headed by a null correlative. This highlights the importance of systematic, experimentally controlled collection of acceptability data at the population level for studying structural properties of sentences, especially as regards theories that make use of abstract structural entities.

\subsection{Reading time patterns and the nominal structure}

The reading time data at the overt correlative region indicate that readers are generally less willing to tolerate the overt correlative in the [long] wh-extraction condition compared to the [short] condition. One possible explanation of this processing pattern in the $[$ long, + corr $]$ condition is in terms of a so-called 
filler-gap effect related to integration of the wh-phrase into the structure. According to one class of parsing theories, upon encountering an initial wh-phrase (a "filler"), the parser attempts to incorporate it into the structure at the first available opportunity (the so called Active Filler Strategy, cf. Frazier 1987, Stowe 1986). When parsing a piece of structure as in (5d), viz. "Kogo $<$ Subject $><$ Verb $>$...", the first potential integration site for the object wh-phrase kogo 'whom' is after the verb (which subcategorizes for NP) on structural grounds. ${ }^{21}$ Encountering the correlative in this position therefore leads to a syntactic reanalysis reflected in greater reading times. In contrast, in the [short, +corr] condition, the point of incorporation of the subject wh-phrase koy 'who' is earlier than the correlative (in fact, before the verb), hence no reanalysis takes place. Thus, the greater reading latency on the overt correlative in the [long, +corr] condition does not necessarily point to an island structure in and of itself but indicates an increased processing complexity associated with reanalysis.

Taken together with the results of the acceptability judgment task, these findings suggest that the increased processing complexity in the [long, +corr] condition at the correlative does not affect global acceptability judgment over and above the degradation that is already there due to the presence of the correlative itself (the [+corr] factor value). In other words, the very presence of an overt correlative independently lowers acceptability regardless of wh-extraction (in both [short] and [long] conditions), but acceptability is not further lowered by the filler-gap effect. This highlights the fundamental divide between the two aspects of linguistic behavior, namely, performance, as tracked by online measures, and competence, as reflected in global acceptability, but also goes against theories in which island effects are attributed to processing effects at large (e.g., Hofmeister, Sag 2010).

We also observed that the time of reading the correlative in the both [short] and [long] condition varies with the verb, and we observed a discernable negative correlation between these two reading time measures. These observations need to be validated further within larger samples of items as well as participants before making firm conclusions about the underlying cause, so here we only offer preliminary remarks regarding their interpretation.

We tentatively suggest that the reading time gradient and the observed negative correlation result from an interaction between the Active Filler Strategy (cf. above) and the so-called verb bias. Verb bias arises in a situation when a verb has more than one subcategorization frame (e.g., the English verb believe can subcategorize for an NP as in John believed the story, or a subordinate clause, as in John believes it is raining) but the probability of occurring with each frame differs, often substantially, in language use (e.g., believe appears to occur twice as likely with a clause than with an NP, hence has a clausal bias; cf. Garnsey et al. 1997). Even though, as mentioned in Section 2, the verbs selected for this study are in principle capable of occurring with the nominal correlative tova, encountering the correlative signals to the reader an NP subcategorization frame which may be preferable for some verbs more than for others. This could be responsible for creating a gradient in reading times for the correlative in the [short, +corr] condition. Now, in the [long, +corr] condition, reading a verb with a more highly preferred NP frame will create a higher expectation for integrating the wh-phrase $\operatorname{kogo}$ (also an NP) due to the Active Filler Strategy than a verb with a less preferred NP frame. This higher expectation could conceivably translate into a higher cost of subsequent reanalysis, when encountering a correlative instead. In contrast, a verb with a less preferred NP subcategorization frame will correspondingly generate less expectation for an NP at the point of reading tova, and therefore there would be less influence of the Active Filler Strategy on the integration of the correlative resulting in relatively smaller reading latencies. Further studies in this direction should include norming studies revealing subcategorization biases for propositional attitude verbs in Bulgarian and test these predictions on a more systematic basis.

\section{Summary and conclusion}

Our experimental study has revealed a pattern of empirical results which suggests that Bulgarian finite clausal complements co-occurring with the overt correlative tova as well as those without the overt correlative entertain an underlying nominal structure along the lines of the "NP-shell" hypothesis. As far

${ }^{21}$ The underlying assumption here is that non-syntactic information such as animacy or plausibility are not necessarily taken into account on the first pass, along the lines of "modular" accounts of sentence processing, cf. references above. 
as we are aware, this finding is novel in Bulgarian syntax. In the grammatical perspective, it opens interesting new venues for exploring locality of syntactic dependencies including degrees of opacity of finite clausal complements. It also invites further work on the syntactic representation of the Bulgarian complementation patterns (NP/ DP vs. a "bare" CP) and their interaction with the semantics of the respective complement-taking predicates. In the realm of psycholinguistics, our study calls for further explorations of subcategorizational biases of Bulgarian verbs and factors affecting integration of an overt correlative into syntactic structure.

\section{Acknowledgments}

Arthur Stepanov's research was supported by the Slovenian Research Agency core funding under research program no. P6-0382 and research project no. J6-1805.

\section{References}

Baayen et al. 2008: Baayen, R. H., D. J. Davidson, D. M. Bates. Mixed-effects Modeling with Crossed Random Effects for Subjects and Items. - In: Journal of Memory and Language, 59 (2008), pp. 390-412.

Emonds 1970: Emonds, J. Root and Structure Preserving Transformations. Cambridge, MA: MIT. Doctoral dissertation.

Fanselow, Weskott 2010: Fanselow, G., T. Weskott. A Short Note on Long Movement in German. - In: Linguistische Berichte, vol. 222, pp. 129-140.

Frazier 1987: Frazier, L. Syntactic Processing: Evidence from Dutch. - In: Natural Language and Linguistic Theory, vol. 5 (4), pp. 519-559.

Garnsey et al. 1997: Garnsey, S.M., N. J. Pearlmutter, E. Myers, M. A. Lotocky. The Contributions of Verb Bias and Plausibility to the Comprehension of Temporarily Ambiguous Sentences. - In: Journal of Memory and Language, vol. 37 (1), pp. 58-93.

Hofmeister, Sag 2010: Hofmeister, P., I. A. Sag. Cognitive Constraints and Island Effects. In: Language, vol. 86 (2), pp. $366-415$.

Krapova 2020: Krapova, I. About "factivity" as a Linguistic Concept and its Implications in Bulgarian. - In: Micheva, V., D. Blagoeva, S. Kolkovska, T. Aleksandrova, H. Deykova (Eds.) Proceedings of the International Annual Conference of the Institute for Bulgarian language. Sofia: Prof. Marin Drinov Publishing House of Bulgarian Academy of Sciences, vol. 1, pp. 58-68.

Kush et al. 2019: Kush, D., T. Lohndal, J. Sprouse. On the Island Sensitivity of Topicalization in Norwegian: An Experimental Investigation. - In: Language, vol. 95 (3), pp. 393-420.

Müller, Sternefeld 1995: Müller, G., W. Sternefeld. Extraction, Lexical Variation and the Theory of Barriers. - In: Urs, E., P. E. Pause, C. Schwarze, A. von Stechow, G. Wienold (Eds.) Lexical Knowledge in the Organization of Language. Amsterdam/Philadelphia: John Benjamins, pp. 35-80.

Rosenbaum 1967: Rosenbaum, P. S. The Grammar of English Predicate Complement Constructions. Cambridge, MA: MIT Press.

Sprouse et al. 2016: Sprouse, J., I. Caponigro, C. Greco, C. Cecchetto. Experimental Syntax and the Variation of Island Effects in English and Italian. - In: Natural Language \& Linguistic Theory, vol. 34, pp. 307-344.

Stepanov 2001: Stepanov, A. Cyclic Domains in Syntactic Theory. Storrs, CT: University of Connecticut. Doctoral dissertation.

Stepanov 2006: Stepanov, A. 'Single Cycle' Languages: Implications for Cyclicity, Recursion and Acquisition. - In: Linguistic Variation Yearbook, vol. 6, pp. 25-71.

Stepanov, Stateva 2006: Stepanov, A., P. Stateva. Successive Cyclicity as Residual wh-scope Marking. - In: Lingua, vol. 116, pp. 2107-2153.

Stepanov et al. 2018: Stepanov, A., M. Mušič, P. Stateva. Two (Non-)islands in Slovenian: A Study in Experimental Syntax. - In: Linguistics, vol. 56 (3), pp. 435-476.

Stowe 1986: Stowe, L. A. Parsing wh-constructions: Evidence for On-line Gap Location. - In: Language and Cognitive Processes, vol. 1, pp. 227-245.

Stowell 1981: Stowell, T. Origins of Phrase Structure. Cambridge, MA: MIT. Doctoral dissertation.

White et al. 2018: White, A. S., V. Hacquard, J. Lidz. Semantic Information and the Syntax of Propositional Attitude Verbs. - In: Cognitive Science, vol. 42 (2), pp. 416-456. 


\title{
ЗА НОМИНАЛНАТА СТРУКТУРА НА НЯКОИ ПОДЧИНЕНИ ДОПЪЛНИТЕЛНИ ИЗРЕЧЕНИЯ В БЪЛГАРСКИЯ ЕЗИК. ЕКСПЕРИМЕНТАЛНО ИЗСЛЕДВАНЕ НА ЕКСТРАКЦИЯТА НА ВЫПРОСИТЕЛНИ ДУМИ
}

\author{
Артур Степанов ${ }^{a}$, Илияна Крыпова \\ Университет в Нова Горица ${ }^{a}, У_{\text {ниверситет Ка' }}$ Фоскари във Венеция ${ }^{6}$ \\ arthur.stepanov@ung.sia ${ }^{a}$,krapova@unive.it ${ }^{\sigma}$
}

\begin{abstract}
Абстракт: В тази работа изследваме възможността някои финитни подчинени допълнителни изречения в българския език, и по-точно онези, които биват селекционирани от предикати за мнение и оценка, да имат номинална структура. В работата се докладват резултатите от пилотен експеримент, чиято цел е да провери приемливостта на екстракцията на въпросителна дума от споменатия тип подчинени допълнителни изречения. Резултатите показват, че както дължината, така и структурата на изречението се отразяват върху приемливостта на к-екстракцията. Фактьт, че както изреченията, въведени с корелативно местоимение това, така и тези, в които местоимението отсъства, образуват островни конфигурации, аналогични на т.нар. сложни NP острови, подкрепя хипотезата, че този тип подчинени изречения имат структура, чиято максимална проекция е не CP, a NP. Данните, получени от анализа на времето за четене на изреченията, позволяват да се направят интересни изводи относно съвместимостта на различни по тип глаголи с корелативно местоимение, въвеждащо подчиненото изречение.
\end{abstract}

Ключови думи: екстракция на к-думи, експериментален синтаксис, предикати за мнение и оценка, български език

Arthur Stepanov

Center for Cognitive Science of Language

University of Nova Gorica

Vipavska 13, SI-5000 Nova Gorica

Slovenia

Iliyana Krapova

Ca'Foscari University of Venice

Dorsoduro 3199

30123 Venice

Italy 